\title{
Survival of isolated human preantral follicles after vitrification: Analyses of morphology and Fas ligand and caspase-3 mRNA expression
}

\author{
Budi Wiweko ${ }^{1,2}$, Soegiharto Soebijanto ${ }^{1}$, Arief Boediono ${ }^{3}$, Muchtaruddin Mansyur $^{4}$, Nuryati C Siregar ${ }^{5}$, Dwi Anita Suryandari ${ }^{6}$, \\ Ahmad Aulia ${ }^{7}$, Tono Djuwantono ${ }^{8}$, Biran Affandi ${ }^{1}$ \\ ${ }^{1}$ Department of Obstetrics and Gynecology, Dr. Cipto Mangunkusumo General Hospital, Faculty of Medicine Universitas Indonesia, Jakarta; ${ }^{2}$ Indonesian \\ Medical Education and Research Institute (IMERI), Faculty of Medicine Universitas Indonesia, Jakarta; ${ }^{3}$ Department of Anatomy, IPB University, Bogor; \\ Departments of ${ }^{4}$ Public Health, ${ }^{5}$ Pathology Anatomy, ${ }^{6}$ Biology, and ${ }^{7}$ Histology, Faculty of Medicine Universitas Indonesia, Jakarta; ${ }^{8}$ Department of \\ Obstetrics and Gynecology, Dr. Hasan Sadikin Hospital, Faculty of Medicine Universitas Padjajaran, Bandung, Indonesia
}

Objective: This study aimed to examine the effect of vitrification on apoptosis and survival in human preantral follicles after thawing. Methods: This experimental study was conducted at an acute tertiary care hospital from March 2012 to April 2013. Ovaries were sliced into $5 \times 5 \times 1-\mathrm{mm}$ pieces and divided into the following three groups: preantral follicle isolation, ovarian tissue vitrification-warming followed by follicle isolation, and immunohistochemistry of fresh ovarian tissue. For statistical analyses, the Student $t$-test, chi-square test, Kruskal-Wallis test, and Kaplan-Meier survival analysis were used.

Results: A total of 161 preantral follicles (70\% secondary) were collected from ovarian cortex tissue of six women between 30 and 37 years of age who underwent oophorectomy due to cervical cancer or breast cancer. There were no significant differences in the follicular morphology of fresh preantral follicles and vitrified follicles after thawing. The mean Fas ligand (FasL) mRNA expression level was $0.43 \pm 0.20$ (relative to $\beta$-actin) in fresh preantral follicles versus $0.51 \pm 0.20$ in vitrified follicles $(p=0.22)$. The mean caspase- $3 \mathrm{mRNA}$ expression level in fresh preantral follicles was $0.56 \pm 0.49$ vs. $0.27 \pm 0.21$ in vitrified follicles ( $p=0.233$ ). One vitrified-thawed secondary follicle grew and developed to an antral follicle within 6 days of culture.

Conclusion:Vitrification did not affect preantral follicle morphology or mRNA expression of the apoptosis markers FasL and caspase-3. Further studies are required to establish whether vitrification affects the outcomes of in vitro culture and the maturation of preantral follicles.

Keywords: Caspase-3; Fas ligand; Human preantral follicles; Vitrification

\section{Introduction}

The incidence of cancer is steadily increasing due to exposure to environmental carcinogenic agents and increases in life expectancy. Simultaneously, advances in chemotherapy and radiotherapy within

Received: March 22, 2019· Revised: April 19, 2019· Accepted: July 15, 2019 Corresponding author: Budi Wiweko

Indonesian Medical Education and Research Institute, Salemba Raya No. 6 Street. Central Jakarta 10430, Indonesia

Tel: +62-8161440025 Fax:+62-3928719 E-mail:wiwekobudi@yahoo.co.id

This is an Open Access article distributed under the terms of the Creative Commons Attribution Non-Commercial License (http://creativecommons.org/licenses/by-nc/4.0/) which permits unrestricted non-commercial use, distribution, and reproduction in any medium, provided the original work is properly cited. the last 10 years have increased the 5 -year survival rate, which has reached $90 \%$ for some types of cancer [1]. Maltaris et al. [1] reported that $20 \%$ of cancers occur in women of child-bearing age and $8 \%$ in women younger than 40 years of age. With improvements in cancer survival rates, many of these young women can expect to have a life after cancer, which may include the desire for a family. However, both chemotherapy and radiation therapy are cytotoxic and damage the ovaries, causing endocrine and reproductive malfunction [2]. Premature ovarian failure secondary to cancer treatment negatively impacts not only fertility, but also tissues that rely on circulating ovarian estrogens, such as bone and the heart.

For young women who wish to preserve their fertility prior to cancer 
treatment, several methods can be offered, including embryo, oocyte, or ovarian tissue freezing. The choice is determined by the type of cancer, patient age and marital status, the timing of the protocol, and the planned chemotherapy and radiation therapy schedule [3]. Ovarian tissue cryopreservation has some advantages over oocyte or embryo freezing; the ovarian cortex contains $90 \%$ of all primordial follicles, which are more resistant to cryo-injury than mature oocytes or embryos [4]. Women with cancer may need chemotherapy and radiation therapy, which increase the risk of premature ovarian failure. Furthemore, in patients with hormone sensitive-cancer or aggressive cancer, it is not an option to use hormone therapy to hyperstimulate the ovaries. In order to prevent premature ovarian failure, ovarian tissue cryopreservation can be done without ovarian hyperstimulation [5-13]. At a later date, thawed oocytes can be used for in vitro fertilization (IVF) and embryos can be transferred, or thawed ovarian tissue can be transplanted to restore fertility and endocrine function [4].

The various drawbacks of embryo, oocyte, and ovarian tissue cryopreservation have led to the investigation of preantral follicle vitrification as an alternative approach to fertility preservation. Preantral follicles 20-200 $\mu \mathrm{m}$ in size are located in the ovarian cortex, and can be isolated from the surrounding tissue mechanically or enzymatically [14]. Preantral follicle vitrification eliminates the technical challenges of ovarian tissue cryopreservation, such as stromal damage and cryoprotectant perfusion, as well as issues with the transplantation of thawed tissue, such as perfusion, hypoxia, and vascular anastomosis [15]. Because vitrified preantral follicles are thawed and cultured in vitro for IVF, they also remove the risk of cancer micrometastasis associated with ovarian tissue transplantation.

Slow freezing and vitrification have been investigated for ovarian tissue cryopreservation $[16,17]$. Slow freezing is a more established protocol, but it is associated with a greater risk of follicle damage because it promotes membrane cell permeability, increases the cell volume, and induces ice crystal formation. Ultra-rapid freezing, or vitrification $\left(-1,500^{\circ} \mathrm{C} / \mathrm{min}\right)$, protocols using cryoprotectant agents lead to a "glass-like" appearance of the cells and protects them from cryo-injury $[18,19]$. Optimization of preantral follicle vitrification methodology is needed to maximize follicle survival after thawing for in vitro culture, maturation, and IVF.

Only a few studies have examined the survival of human preantral follicles after vitrification and thawing [20,21]. Preantral follicle survival is related to apoptosis of the oocyte and its surrounding support cells. Apoptosis in the follicle is initiated in mitochondria by the intrinsic pathway [13] or via the extrinsic pathway with the activation of membrane receptors [22]. Both the intrinsic and extrinsic pathways of apoptosis activate caspase- 3 to stimulate the caspase cascade $[23,24]$. In this study, we compared the survival of fresh and vitrified-thawed human preantral follicles isolated from fresh ovarian cortical pieces based on morphology (basal membrane, granulosa cells, zona pellucida, and oocytes), expression of apoptosis-related genes and proteins, and outcomes of in vitro follicle culture.

\section{Methods}

\section{Study design}

We compared markers of apoptosis and survival in fresh and vitrified-thawed preantral follicles isolated from fresh ovarian cortical fragments (Figure 1). The study design and use of human ovarian tissue was approved by the Ethical Research Committee of the Faculty of Medicine at Universitas Indonesia. After obtaining written informed consent, ovaries were removed from women undergoing oophorectomy after a diagnosis of cervical or breast cancer at Dr. Cipto Mangunkusumo General Hospital and Fatmawati General Hospital in Jakarta. Immediately after removal, ovaries were suspended in Dulbecco's phosphate-buffered saline (DPBS) solution at $37^{\circ} \mathrm{C}$ and transferred to the laboratory within 15 minutes.

\section{Statistical analysis}

The Student $t$-test was used to assess the relationship between follicle vitrification and morphology scores, as well as the relationship between follicle vitrification and Fas ligand (FasL) and caspase-3 gene expression. The relationship between the isolation method and preantral follicle count was analyzed using the Kruskal-Wallis test. The chi-square test was used to evaluate the relationship between each category of isolated preantral follicle and the preantral follicle stage. A Kaplan-Meier survival analysis was conducted for the fresh preantral follicles and the post-vitrification follicles under culture condition.

\section{Sample characteristics}

Ovaries were isolated from six women, 30-37 years of age, who underwent oophorectomy due to cervical cancer or breast cancer. From three of the six patients, we obtained serum samples and measured anti-Müllerian hormone (AMH) levels using a Beckman-Coulter second-generation AMH assay (Beckman Coulter Inc., Brea, CA, USA).

\section{Ovarian cortex excision and vitrification}

A tissue slicer (Square Measure, Kitazato, Japan) was used to cut the ovarian cortex into $5 \times 5 \times 1-\mathrm{mm}$ pieces as described previously by Kagawa et al. [19]. Three pieces of ovarian cortex from each patient were directly randomized to undergo immunohistochemistry, preantral follicle isolation, and ovarian tissue vitrification-warming followed by follicle isolation. For vitrification, the ovarian cortex pieces were equilibrated in 7.5\% ethylene glycol (EG) and 7.5\% dimethyl sulfoxide (DMSO) for 25 minutes followed by a second equilibration in $20 \%$ EG and $20 \%$ DMSO with $0.5 \mathrm{~mol} / \mathrm{L}$ sucrose for 15 minutes. The 


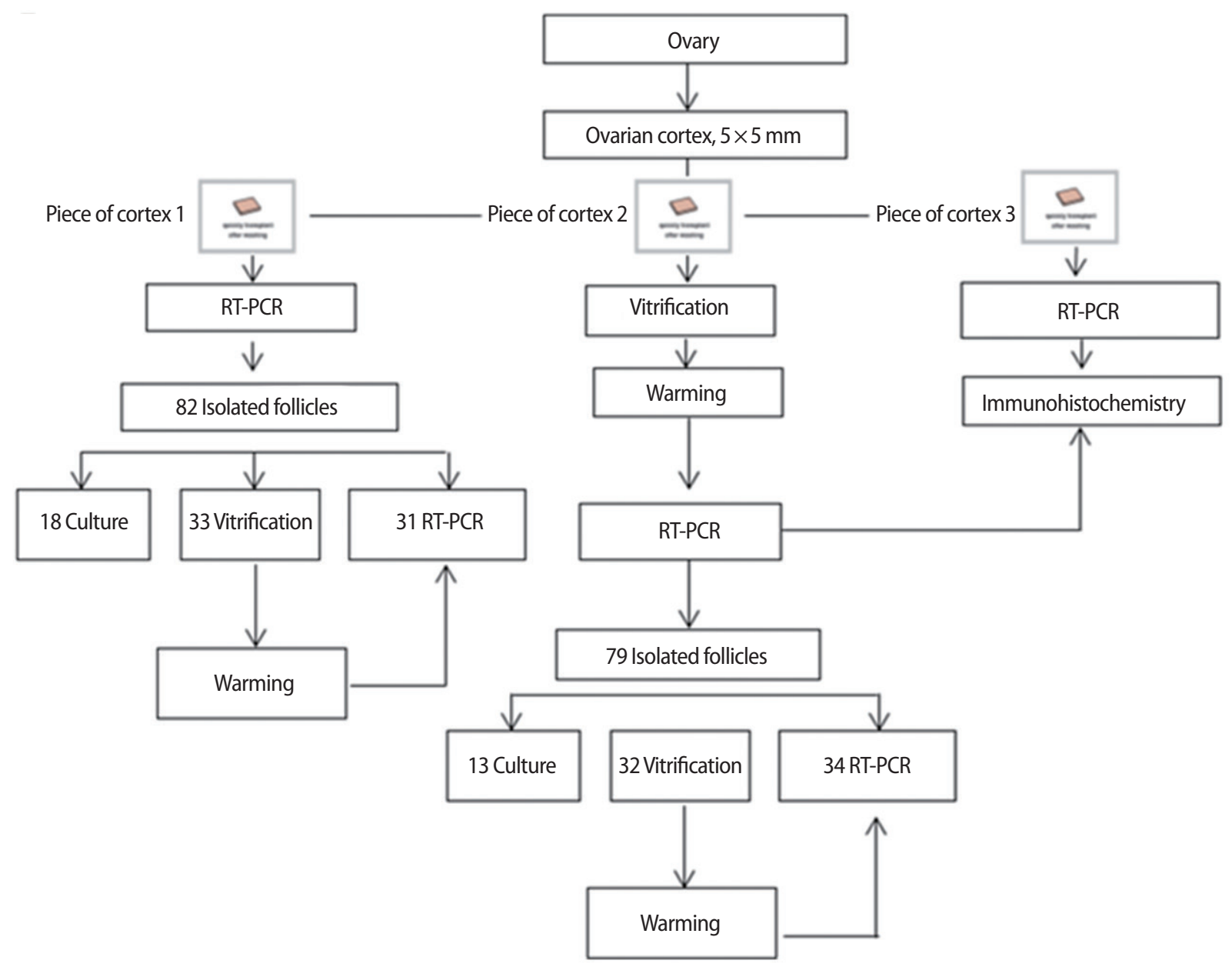

Figure 1. Study design flowchart. RT-PCR, real-time polymerase chain reaction.

ovarian cortex pieces were then placed in a minimum volume of solution onto a thin metal strip (Cryotissue, Kitazato BioPharma, Fujinomiya, Japan) and submerged directly into liquid nitrogen. For warming, the tissue pieces were immediately covered with vitrification thawing medium at room temperature until the tissue was released from the Cryotissue device. The first vitrification thawing medium was composed of $1.0 \mathrm{~mol} / \mathrm{L}$ sucrose. Then, the ovarian strips were transferred into warming solution 1 and 2 containing $0.5 \mathrm{M}$ sucrose for 5 minutes each at room temperature. The ovarian cortical pieces were then ready to use for preantral follicle isolation.

\section{Follicle isolation}

Preantral follicles were isolated from both fresh and vitrified-thawed ovarian cortex samples using three different procedures. In the first group, isolation was performed using $0.04 \mathrm{mg} / \mathrm{mL}$ Liberase $\mathrm{DH}$ (Roche, Indianapolis, IN, USA) according to the method described by Dolmans et al. [25]. In the second group, isolation was performed using 0.04 $\mathrm{mg} / \mathrm{mL}$ Liberase $\mathrm{DH}+10 \mathrm{IU}$ of DNAse, and in the third group, isolation was performed using $0.5 \mathrm{mg} / \mathrm{mL}$ collagenase+10 IU of DNAse.
The ovarian tissue was then incubated in a water bath at $37^{\circ} \mathrm{C}$ for 75 minutes in the first group, 60 minutes in the second group, and 45 minutes in the third group. The ovarian digestion reaction mixture was periodically shaken and drawn up every 15 minutes with a pipette to mechanically disrupt the digested tissue. Digestion was completed by the addition of an equal volume of DPBS at $4^{\circ} \mathrm{C}$ supplemented with 10\% fetal bovine serum (FBS) (Gibco, Thermo Fisher Scientific, Waltham, MA, USA). The resulting suspension was centrifuged at $50 \times g$ for 10 minutes at $4^{\circ} \mathrm{C}$. The supernatant was discarded, the pellet was filtered through a cell strainer and transferred to Petri dishes, and the presence of follicles was investigated under a stereomicroscope. Preantral follicles isolated from fresh ovarian tissue were subjected to morphological analysis, in vitro culture, vitrification, and real-time polymerase chain reaction (RT-PCR).

\section{Preantral follicle vitrification}

Vitrification of preantral follicles isolated from fresh ovarian cortex (Figure 1) was performed according to the method proposed by Kagawa et al. [19] using cryovials. At the time of vitrification, follicles 
were transferred into equilibration solution consisting of 7.5\% EG and $7.5 \%$ DMSO for 25 minutes. After initial shrinkage, the follicles regained their original volume, and were transferred into vitrification solution consisting of $20 \% \mathrm{EG}, 20 \% \mathrm{DMSO}$, and $0.5 \mathrm{~mol} / \mathrm{L}$ sucrose. After incubation for 15 minutes, the follicles were loaded into a cryovial and plunged into liquid nitrogen. For warming, the preantral follicles were taken from the liquid nitrogen tube, then immediately introduced into a heated warming solution medium at $37^{\circ} \mathrm{C}$ until the tissue was released from the cryovial. The follicles were then transferred into a diluent solution medium ( $1.0 \mathrm{~mol} / \mathrm{L}$ sucrose) for 3 minutes at $37^{\circ} \mathrm{C}$. Then, they were transfered into warming solutions 1 and $2(0.5$ $\mathrm{mol} / \mathrm{L}$ sucrose) at room temperature for 5 minutes. After warming, the preantral follicles immediately underwent RNA isolation, followed by RT-PCR.

\section{Morphological assessment}

In the fresh and vitrified-thawed ovarian cortex samples, the preantral follicle basal membrane, granulosa cells, zona pellucida, and oocytes of preantral follicles were evaluated under a light microscope. Isolated fresh and vitrified-thawed preantral follicle morphology was evaluated under an inverted microscope. A morphological scoring criterion was developed for the basement membrane, granulosa cells, zona pellucida, and oocytes. The total possible score for follicle morphology was 4 ( 1 for an intact basement membrane, regular granulosa cells, intact zona pellucida, and completely regular oocyte, and 0 for the opposite condition of each criterion).

\section{Immunohistochemistry}

Six to eight sections from the middle of every fresh and vitrifiedthawed ovarian fragment were immunostained with antibodies against caspase- 3 and FasL. The antibodies used were mouse anti human monoclonal caspase- 3 and mouse anti human monoclonal FasL (Biogenex, Fremont, CA, USA). All parrafin-embedded samples were deparaffized and rehydrated. Antigen retrieval was performed by microwaving the slides in $1 \%$ sodium citrate at the high setting for 20 minutes. The slides were then immersed in $0.5 \% \mathrm{H}_{2} \mathrm{O}_{2}$ to quench endogenous peroxidase. The sections were incubated with blocking solution for 1 hour, followed by overnight incubation with primary antibodies against caspase- 3 and FasL at $4^{\circ} \mathrm{C}$. After being incubated in TrekAvidin-horseradish peroxidase to bind the antibodies with the chromogen, the sections were stained with 3,3'-diaminobenzidine as a chromogen for 5 minutes. Blood vessels were used as positive and negative controls, since it has been demonstrated that smooth-muscle cells of blood vessels express FasL [26], while caspase-3 expression is proven to be associated with the normal intima of blood vessels [27]. The antibodies against caspase-3 and FasL were omitted in the negative control tissue.

\section{Real-time polymerase chain reaction}

FasL and caspase-3 expression levels in the isolated fresh and vitrified-thawed preantral follicles were determined by RT-PCR (Figure 1). Preantral follicles were suspended in lysis binding buffer solution and digested by homogenization. Total RNA was extracted using the High Pure RNA Isolation Kit (Roche, Mannheim, Germany) according to the manufacturer's instructions. The FasL and caspase-3 genes were amplified using specific primers, and the mRNA expression from both groups was read on the 50th cycle of amplification. $\beta$-actin was used as the reference gene for each sample.

The sequences of the primers used for FasL, caspase- 3 , and $\beta$-actin expression by RT-PCR were as follows. FasL: forward (FW), $5^{\prime}-\mathrm{GCA}$ GCC CTT CAA TTA CCC AT-3'; reverse (RV), 5'-CAG AGG TTG GA-3'C AGG GAA GAA-3' (101 bp); caspase 3: FW, 5'-TGC ATA CTC CAC AGC ACC TGG TTA-3'; RV, 5'-CAT GGC ACA AAG CGA CTG GAT GAA-3' (82 bp); $\beta$-actin: FW, 5'-ACTCTTCCAGCCTTCCTTCC-3'; RV, 5' - AGCACTGTGTTGGCGTACAG-3' (117 bp).

\section{In vitro follicle culture}

This study used alpha minimal essential medium as the culture medium (a-MEM; Gibco), supplemented with 5\% FBS, $100 \mathrm{mlU} / \mathrm{mL}$ recombinant follicle-stimulating hormone (Gonal F; Merck Serono, Darmstadt, Germany), $5 \mu \mathrm{L} / \mathrm{mL}$ insulin, $5 \mu \mathrm{L} / \mathrm{mL}$ transferrin, $5 \mu \mathrm{L} / \mathrm{mL}$ selenium (Merck Serono), and $100 \mu \mathrm{L} / \mathrm{mL}$ streptomycin (Gibco). Preantral follicles with normal morphology were cultured in four-well culture dishes containing $1 \mathrm{~mL} /$ well of culture medium at $37^{\circ} \mathrm{C}$ in $5 \% \mathrm{CO}_{2}$. The follicles were incubated for 8-10 days. Half of the medium was exchanged every other day and the diameter of the follicles was measured using an inverted microscope. Two perpendicular diameters were measured using a calibrated ocular micrometer at $10 \times 40 \mu \mathrm{m}$ magnification to assess the growth of each follicle and the oocyte diameter. Viable follicles were defined as those that retained an oocyte completely embedded within the granulosa cell mass.

\section{Results}

\section{Sample characteristics}

Of the three patients in whom serum AMH levels were measured, the highest level of AMH was $6.7 \mathrm{ng} / \mathrm{mL}$. A total of 82 preantral follicles were isolated from the fresh ovarian cortex samples, and 79 preantral follicles were isolated from vitrified-thawed ovarian cortex samples (Tables 1,2).

\section{Preantral follicle isolation from fresh ovarian cortex}

The proportion and distribution of preantral follicles successfully isolated from fresh ovarian cortex samples using three proteolytic enzymes can be seen in Table 3. No difference was found in the number and type of preantral post-isolation follicles using the three pro- 
Table 1. Subject characteristics

\begin{tabular}{|c|c|c|c|c|c|c|}
\hline Characteristics & Subject 1 & Subject 2 & Subject 3 & Subject 4 & Subject 5 & Subject 6 \\
\hline Age (yr) & 37 & 35 & 37 & 31 & 37 & 30 \\
\hline Type of cancer & Cervical cancer & Cervical cancer & Cervical cancer & Cervical cancer & Cervical cancer & Breast cancer \\
\hline Anti-Müllerian hormone & NA & NA & NA & 6.7 & 4.08 & 0.16 \\
\hline \multicolumn{7}{|c|}{$\begin{array}{l}\text { No. of preantral follicles from fresh ovary samples } \\
(\mathrm{n}=82)\end{array}$} \\
\hline Primordial & 0 & 0 & 0 & 6 & 0 & 0 \\
\hline Primary & 0 & 0 & 0 & 15 & 0 & 3 \\
\hline Secondary & 0 & 4 & 0 & 51 & 0 & 0 \\
\hline Total & 0 & 4 & 0 & 72 & 1 & 3 \\
\hline \multicolumn{7}{|c|}{$\begin{array}{l}\text { No. of preantral follicles from warmed-vitrified ovary } \\
\text { samples }(n=79)\end{array}$} \\
\hline Primordial & 0 & 0 & 0 & 4 & 0 & 0 \\
\hline Primary & 0 & 3 & 0 & 20 & 0 & 1 \\
\hline Secondary & 0 & 4 & 0 & 46 & 1 & 0 \\
\hline Total & 0 & 7 & 0 & 70 & 1 & 1 \\
\hline
\end{tabular}

NA, not available.

Table 2. Distribution of isolated preantral follicles from fresh and vitrified-thawed ovarian cortex samples

\begin{tabular}{|c|c|c|c|c|c|}
\hline \multirow{2}{*}{ Variable } & \multicolumn{3}{|c|}{ Preantral follicle stage } & \multirow{2}{*}{ Total } & \multirow{2}{*}{$p$-value $e^{a)}$} \\
\hline & Primordial & Primary & Secondary & & \\
\hline Group & & & & & 0.998 \\
\hline Fresh ovarian cortex & 6 & 18 & 58 & 82 & \\
\hline Vitrified-thawed ovarian cortex & 4 & 24 & 51 & 79 & \\
\hline Age (yr) & & & & & 1.000 \\
\hline$<35$ & 10 & 39 & 99 & 148 & \\
\hline$\geq 35$ & 0 & 3 & 10 & 13 & \\
\hline $\mathrm{AMH}(\mathrm{ng} / \mathrm{mL})$ & & & & & 0.961 \\
\hline$<1.4$ & 0 & 4 & 4 & 8 & \\
\hline$\geq 1.4$ & 10 & 35 & 97 & 142 & \\
\hline No data & 0 & 3 & - & 11 & \\
\hline
\end{tabular}

$\mathrm{AMH}$, anti-Müllerian hormone.

${ }^{a}$ Chi-square test.

Table 3. The number and distribution of post-isolation preantral follicles from fresh ovarian cortex samples using three proteolytic enzymes

\begin{tabular}{|c|c|c|c|c|c|c|}
\hline \multirow{2}{*}{ No. } & \multirow{2}{*}{ Technique } & \multirow{2}{*}{ No. of follicles } & \multicolumn{3}{|c|}{ Type of follicle } & \multirow{2}{*}{$p$-value } \\
\hline & & & Primordial & Primary & Secondary & \\
\hline 1 & Liberase $\mathrm{DH} 75^{\prime}$ & 10 & 0 & 4 & 6 & 0.013 \\
\hline 2 & Liberase DH+DNase 60' & 32 & 1 & 10 & 21 & \\
\hline 3 & Collagenase+DNase $45^{\prime}$ & 40 & 5 & 4 & 31 & \\
\hline Total & & 82 & 6 & 18 & 58 & \\
\hline
\end{tabular}

Kruskal-Wallis test.

teolytic enzymes from the fresh ovarian cortex samples. In addition, DNAse facilitated the follicle isolation process, with a shorter incubation time than the group without DNAse.

\section{Evaluation of morphological and molecular markers of apoptosis in preantral follicles from fresh and vitrified- thawed ovarian cortex}

No significant differences were found in basal membrane, granulosa cell, zona pellucida, and oocyte morphology in the preantral folli- cles between the fresh and vitrified-thawed ovarian cortical fragments (Figure 2). The immunohistochemistry of FasL and caspase-3 in fresh ovarian cortex and vitrified-thawed ovarian cortex samples showed no significant differences (Figures 3-6). Some scoring systems used to evaluate the immunohistochemistry of progesterone and estrogen receptors are the Allred score, immunoreactive score, and the $\mathrm{H}$-score. A qualitative evaluation of apoptosis marker staining was conducted in this study using the $\mathrm{H}$-score, defined as:

$$
\left[\mathrm{H} \text {-score }=\sum \mathrm{Pi}(\mathrm{i}+1)\right]
$$


Table 4. Mean H-scores for the expression of apoptosis markers in preantral follicles

\begin{tabular}{lccc}
\hline Immunohistochemistry mean H-score & Fresh ovarian cortex & Vitrified-thawed ovarian cortex & $p$-value \\
\hline FasL & $50.02 \pm 0.81$ & $47.08 \pm 4.13$ & 0.211 \\
Caspase-3 & $23.67 \pm 1.60$ & $20.54 \pm 1.69$ & 0.080 \\
\hline
\end{tabular}

Values are presented as mean \pm standard deviation. FasL, Fas ligand.
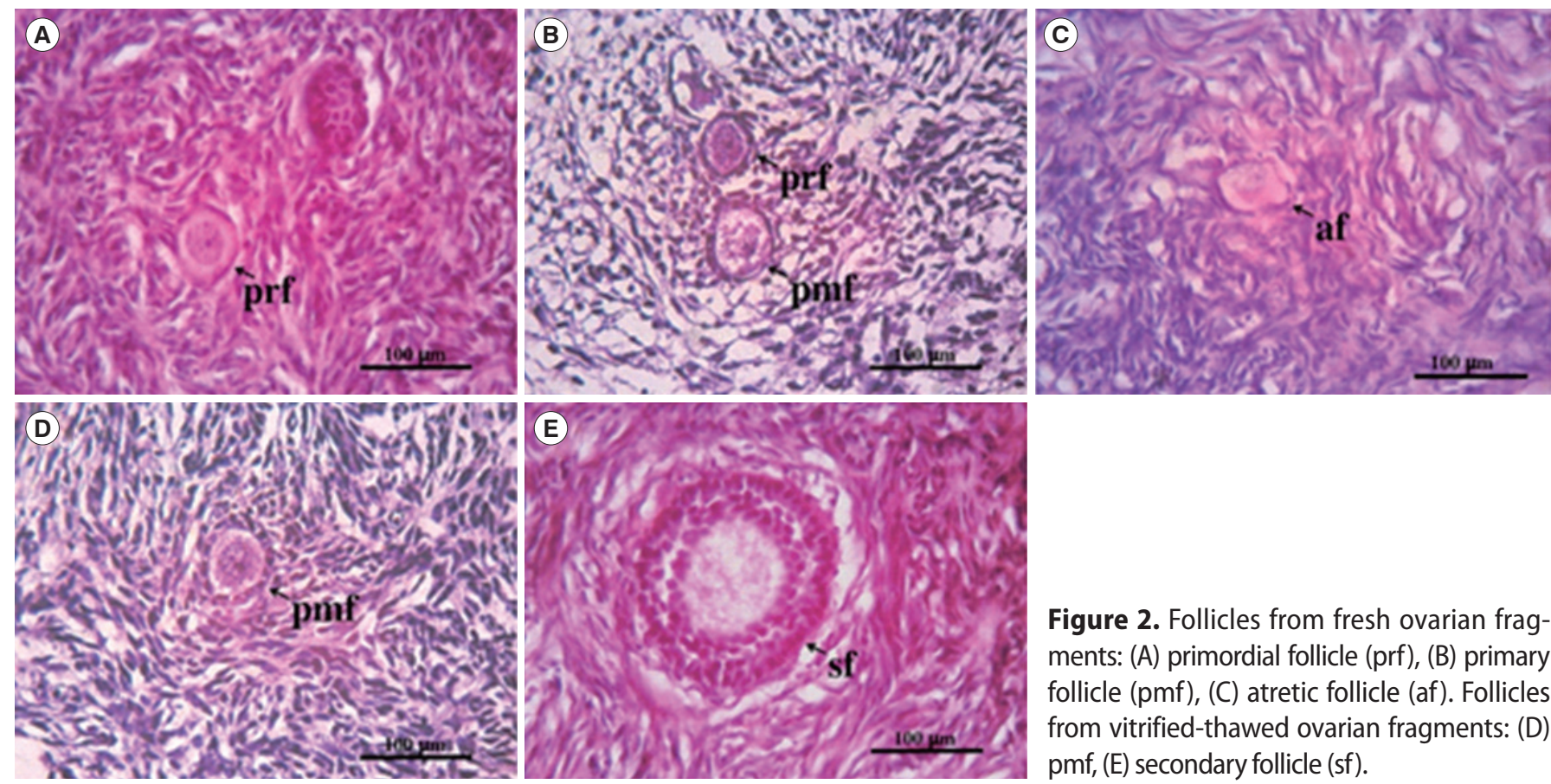

Figure 2. Follicles from fresh ovarian fragments: (A) primordial follicle (prf), (B) primary follicle (pmf), (C) atretic follicle (af). Follicles from vitrified-thawed ovarian fragments: (D) $\mathrm{pmf}$, (E) secondary follicle (sf).

Pi, percentage of stained follicles; i, intensity of stained follicles

The intensity of the stained follicles was defined on a scale ranging from 0 to 3 ( 0 , negative; +1 , weak; +2 , moderate; +3 , strong). The $\mathrm{H}$ score ranges from 0 to 300 ( 0 , no staining; 300 , diffuse staining) and consists of two categorical scores (negative $\leq 1$, positive $\geq 1$ ). The mean $\mathrm{H}$-score for FasL immunohistochemistry in the preantral follicles from fresh ovarian cortex samples was $50.02 \pm 0.81$ vs. $47.08 \pm 4.13$ for the preantral follicles from vitrified-thawed ovarian cortex samples $(p=0.211)$. The mean $\mathrm{H}$-score for caspase-3 immunohistochemistry in the preantral follicles from fresh ovarian cortex samples was $23.67 \pm 1.60$ vs. $20.54 \pm 1.69$ for the preantral follicles from vitrifiedthawed ovarian cortex samples $(p=0.080$ ) (Table 4).

\section{Morphological evaluation of preantral follicles isolated from fresh and vitrified-thawed ovarian cortex}

Secondary follicles were the most frequent type of follicles isolated from the ovarian cortex (Tables 2, 3). Oocytes whose intact zona pellucida was surrounded by two layers of granulosa cells and an intact basal membrane were classified as secondary follicles (Figure 7).
Table 5. Morphological evaluation of freshly isolated vitrified-thawed preantral follicles

\begin{tabular}{lc}
\hline Follicle type & Follicular diameter $(\mu \mathrm{m})$ \\
\hline Primordial follicle & $27.25 \pm 1.89$ \\
Primary follicle & $96.00 \pm 4.00$ \\
Secondary follicle & $125.55 \pm 17.63$ \\
\hline
\end{tabular}

Values are presented as mean \pm standard deviation.

The mean morphology score for primordial, primary, and secondary follicles isolated from fresh ovarian cortex samples was $2.75 \pm 1.5$, $2.83 \pm 1.15$, and $2.83 \pm 1.15$, respectively. In comparison, the mean morphology score for primordial, primary, and secondary follicles isolated from vitrified-thawed ovarian cortex samples was $3.5 \pm 1.0,2.79 \pm 1.44$, and $3.07 \pm 1.04$, respectively (Figure 8 ). There was no significant difference in the mean morphology score for preantral follicles isolated from fresh or vitrified-thawed ovarian cortex samples (unpaired Student $t$-test).

\section{Morphological evaluation of freshly isolated vitrified- thawed preantral follicles}

Vitrification was performed on 65 preantral follicles isolated from fresh 

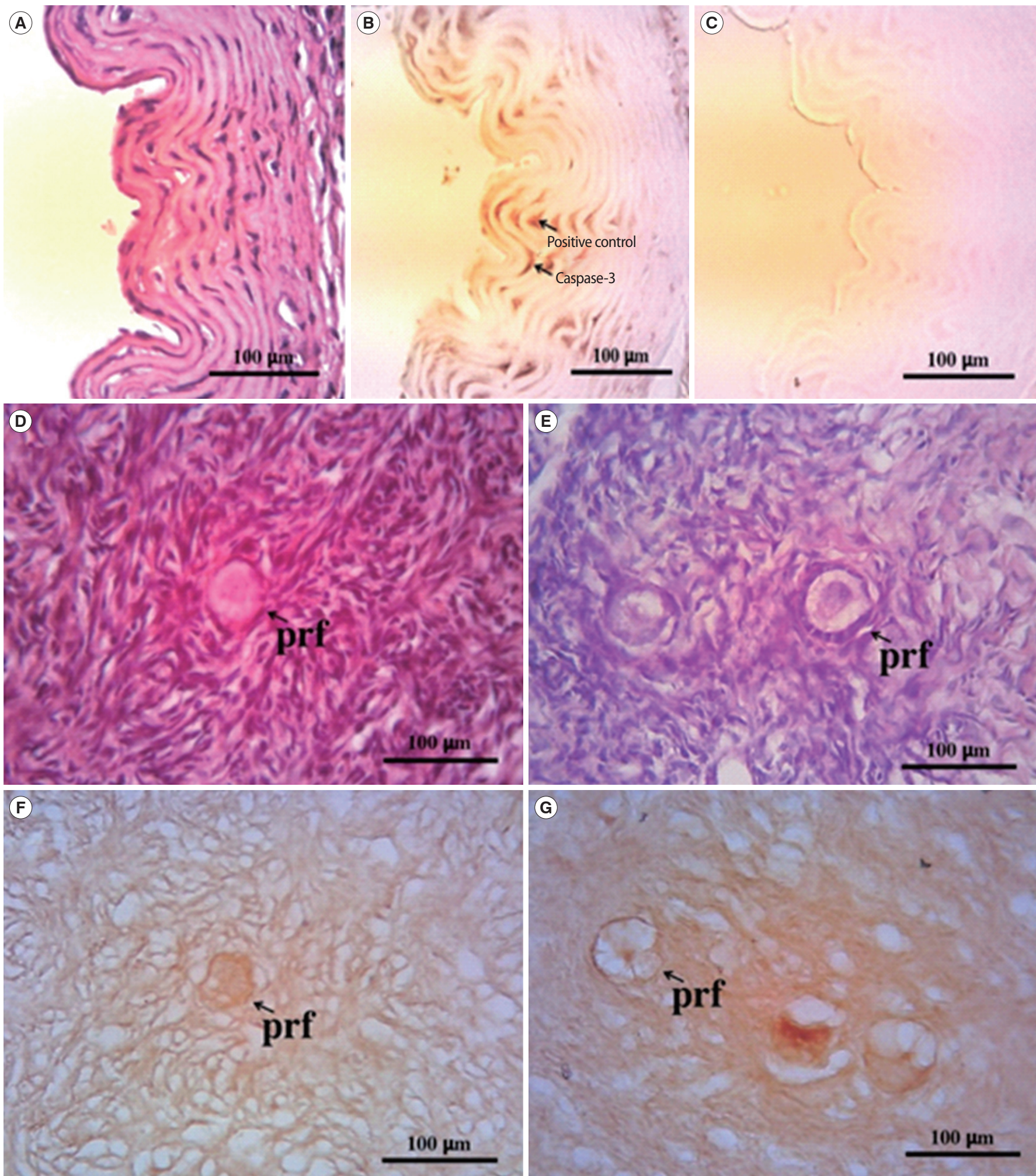

Figure 3. Expression of caspase-3 in fresh ovarian cortex. (A) H\&E staining of blood vessels (control). (B) Caspase-3 expression in blood vessels (positive control). (C) Lack of caspase-3 expression (negative control). (D, E) H\&E staining of fresh ovarian cortex. (F, G) Caspase-3 expression in granulosa cells, oocyte, and stroma of primary follicles. prf, primordial follicle.

ovarian cortex samples. The storage time after vitrification varied between 1 and 3 months depending on the time when the sample was taken. There were no significant morphological differences between the isolated fresh and vitrified-thawed preantral follicles (Table 5, Figure 9). 


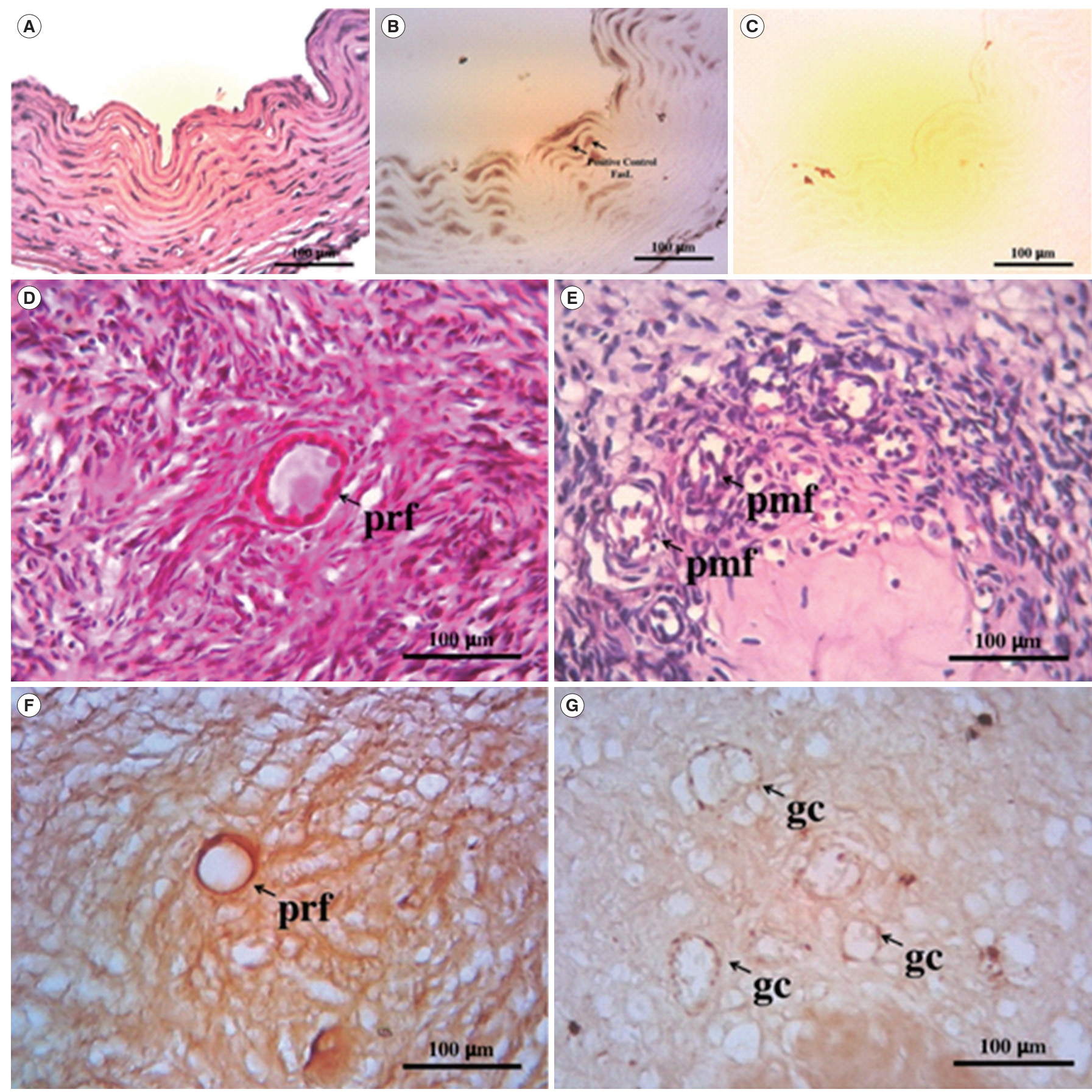

Figure 4. Expression of Fas ligand (FasL) in fresh ovarian cortex. (A) H\&E staining of blood vessels (control). (B) FasL expression in blood vessels (positive control). (C) Lack of FasL expression (negative control). (D, E) H\&E staining of fresh ovarian cortex. (F, G) FasL expression on granulosa cells (gc). prf, primordial follicle; pmf, primary follicle.

\section{Apoptotic markers in isolated preantral follicles}

The expression levels of FasL and caspase-3 mRNA in the isolated fresh and vitrified-thawed preantral follicles were not significantly different. The mean FasL mRNA expression level in the fresh isolated preantral follicles was $0.43 \pm 0.20$ (relative to $\beta$-actin) vs. $0.51 \pm 0.20$ in the vitrified-thawed group $(p=0.22)$. The mean caspase-3 mRNA expres- sion level in the fresh isolated preantral follicles was $0.56 \pm 0.49$ vs. $0.27 \pm 0.21$ in the vitrified-thawed group $(p=0.233$ ).

\section{In vitro culture of isolated preantral follicles}

Out of the 18 preantral follicles isolated on day 0 , only one follicle from a fresh ovarian cortex sample developed into an antral-stage 

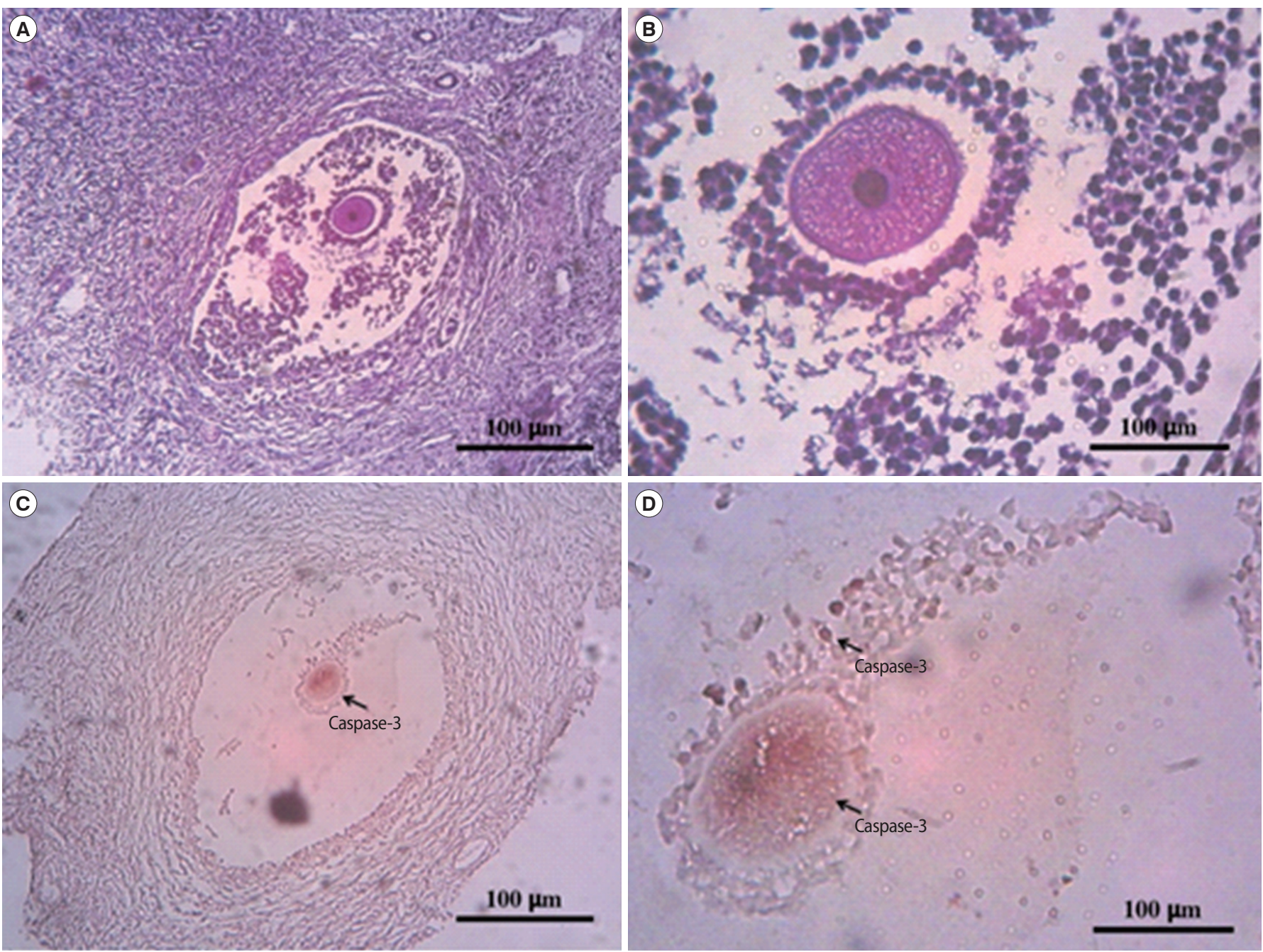

Figure 5. Expression of caspase-3 in vitrified-thawed ovarian cortex. (A, B) H\&E staining of fresh ovarian cortex. (C, D) Expression of caspase-3 in oocytes.
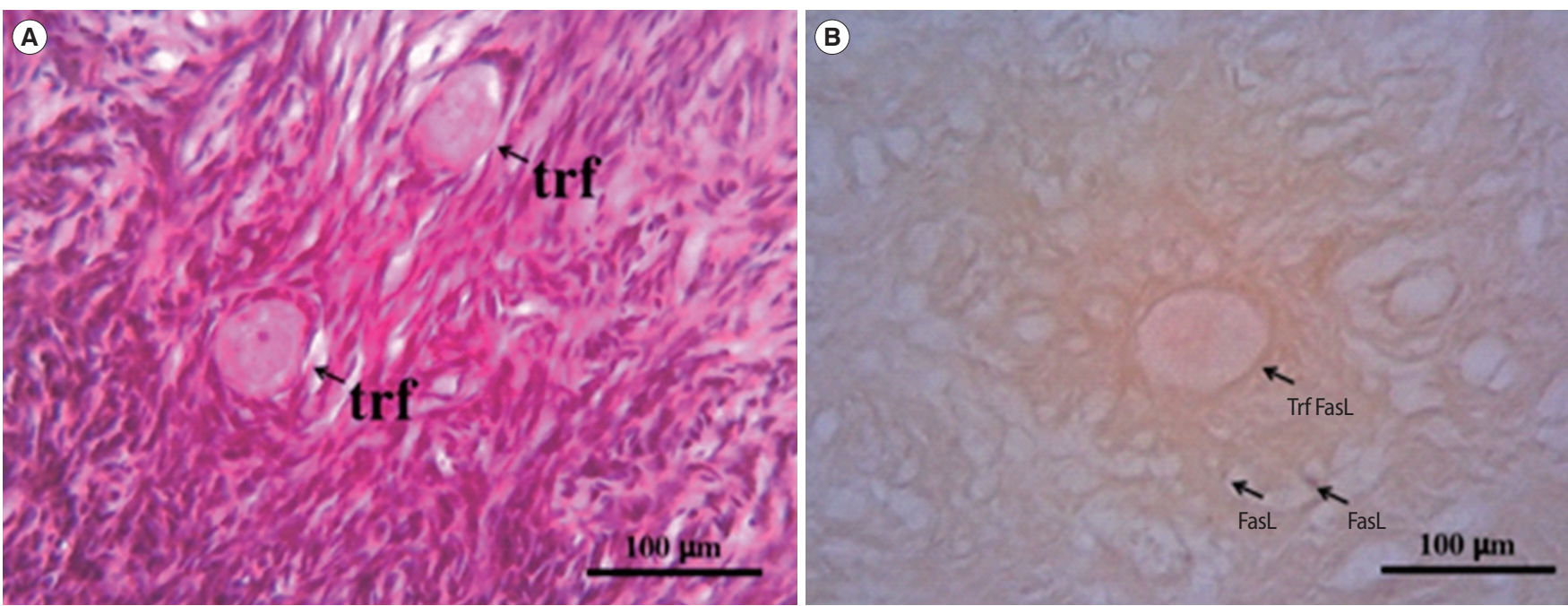

Figure 6. Expression of Fas ligand (FasL) in vitrified-thawed ovarian cortex. (A) H\&E staining of fresh ovarian cortex. (B) FasL expression in a primary follicle. trf, transitional follicle. 

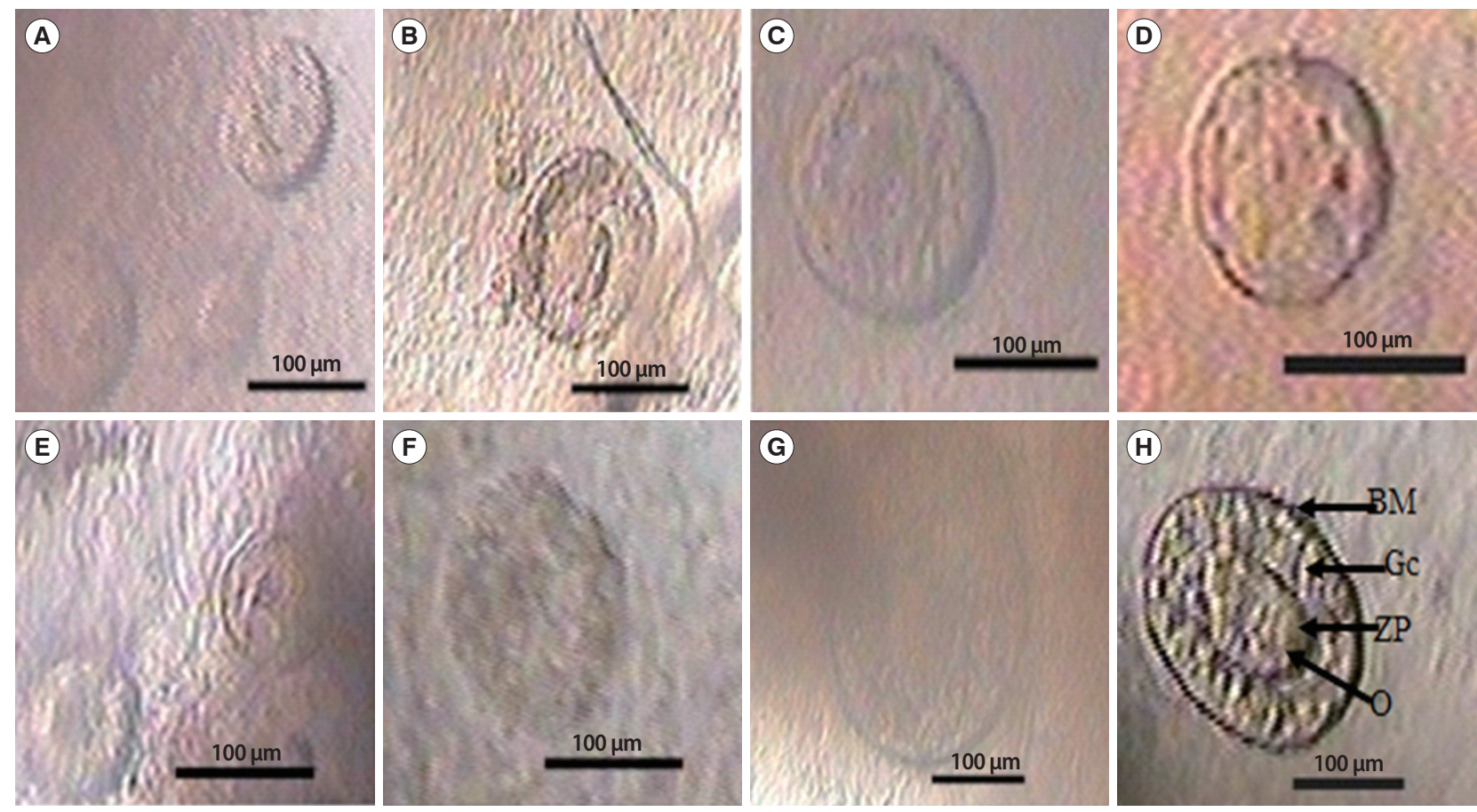

Figure 7. Preantral follicles from fresh ovarian cortex (A-D) and vitrified-thawed ovarian cortex (E-H). BM, basal membrane; Gc, granulosa cell; ZP, zona pellucida; $\mathrm{O}$, oocyte.
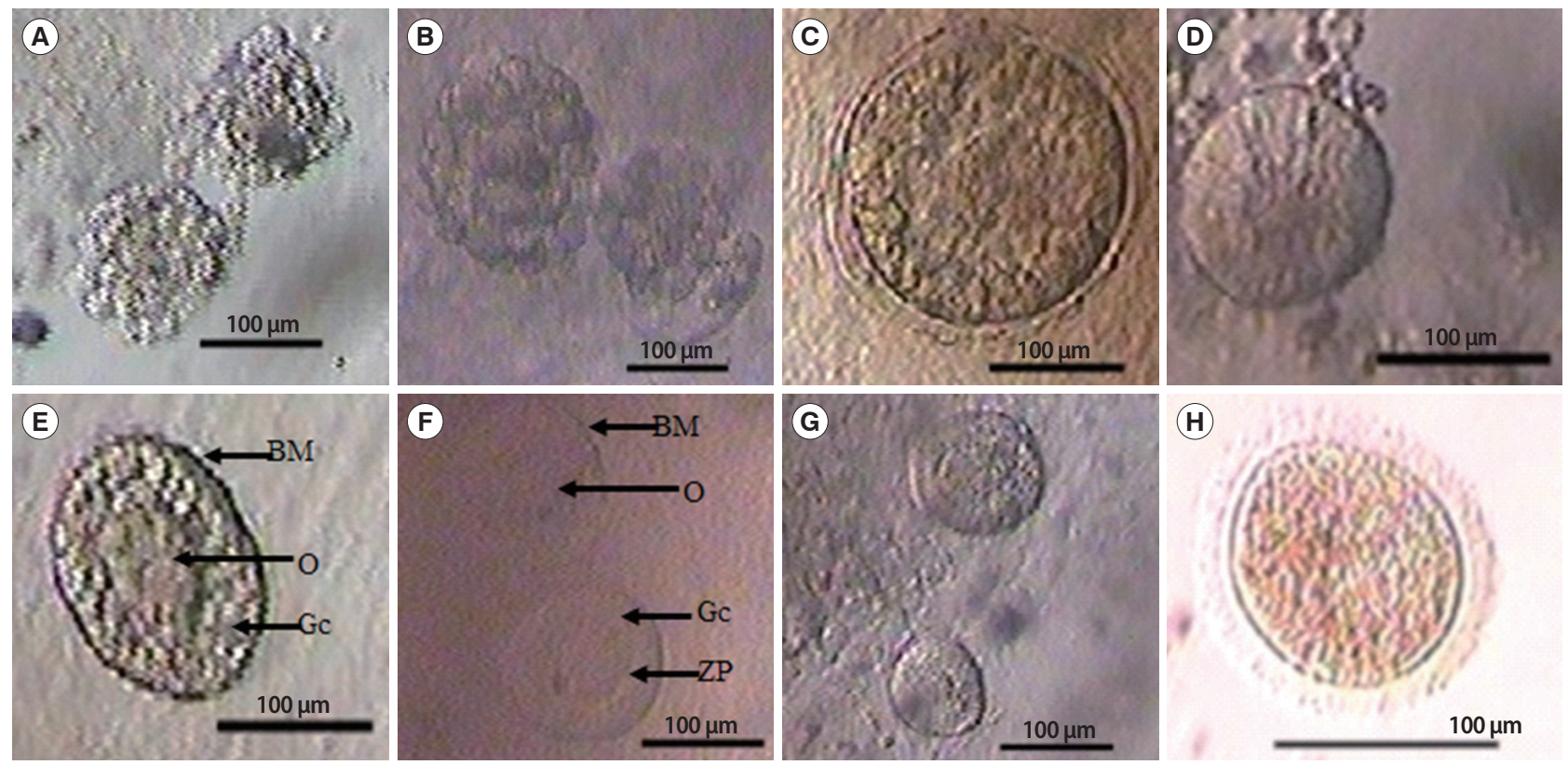

Figure 8. (A, B) Primordial follicle. (C, D) Primary follicle. (E-G) Secondary follicle. (H) Oocyte. BM, basal membrane; O, oocyte; Gc, granulosa cell; ZP, zona pellucida.

follicle after 8 days of culture. The yield of follicles isolated from women younger than 35 years old was markedly higher in comparison with those isolated from older women. Furthemore, a higher yield of follicles was observed in participants with a serum AMH level above $1.4 \mathrm{ng} / \mathrm{mL}$ than in those with lower AMH serum levels (Table 6).

One secondary follicle isolated from a fresh ovarian cortex sample developed to the antral stage within 6 days of culture. On the second day of culture, granulosa cells proliferated and produced antral fluid within a well-defined antrum (Figure 10). The follicle diameter increased from $100 \mu \mathrm{m}$ to $180 \mu \mathrm{m}, 290 \mu \mathrm{m}$, and $400 \mu \mathrm{m}$ within 6 days of culture. The oocyte diameter was measured every other day, with an average of $98-100 \mu \mathrm{m}$. 
Table 6. In vitro culture of isolated preantral follicles

\begin{tabular}{|c|c|c|c|c|c|c|}
\hline \multirow{2}{*}{ Variable } & \multicolumn{5}{|c|}{ Culture day } & \multirow{2}{*}{ Description } \\
\hline & 0 & 2 & 4 & 6 & 8 & \\
\hline Age (yr) & & & & & & 1 Antral follicle growth \\
\hline$\geq 35$ & 5 & 5 & 2 & 0 & 0 & \\
\hline $\mathrm{AMH}(\mathrm{ng} / \mathrm{mL})$ & & & & & & 1 Antral follicle growth \\
\hline$<1.4$ & 2 & 0 & 0 & 0 & 0 & \\
\hline No data & 5 & 5 & 2 & 0 & 0 & \\
\hline
\end{tabular}

AMH, anti-Müllerian hormone.
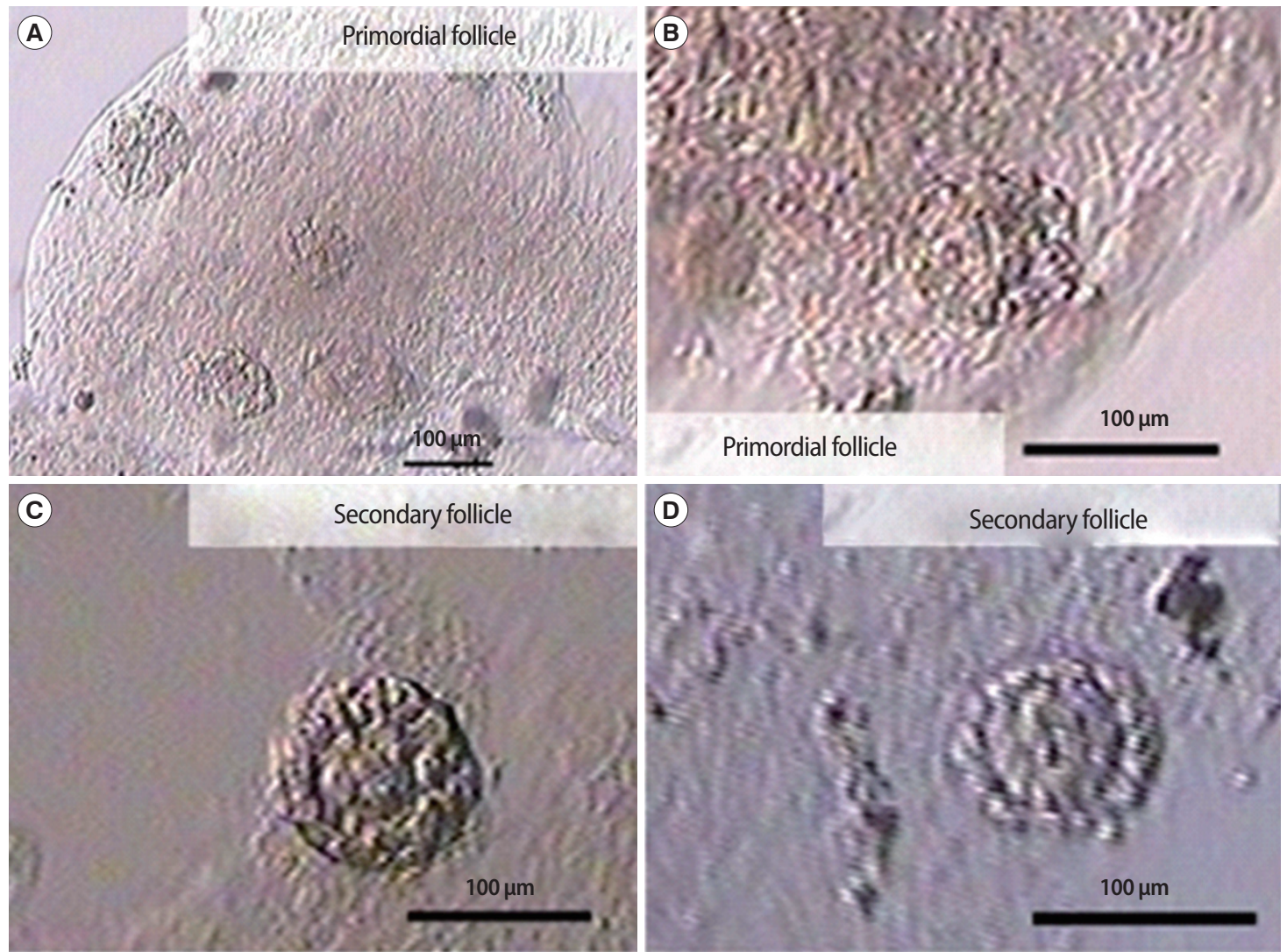

Figure 9. Vitrified-thawed preantral follicles isolated from fresh ovarian fragments. (A) Primordial follicle. (B) Primary follicle. (C, D) Secondary follicle.
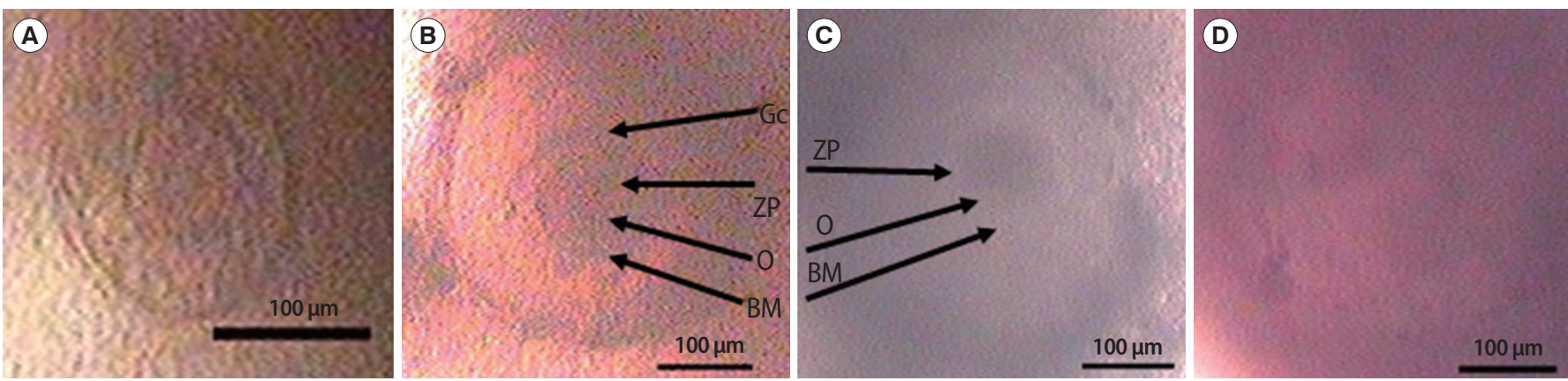

Figure 10. In vitro culture of preantral follicles from fresh ovarian cortex. Culture of follicles on day 2 (A), day 4 (B), day 6 (C), and day 8 (D). Gc, granulosa cell; $\mathrm{O}$, oocyte; $\mathrm{ZP}$, zona pellucida; $\mathrm{BM}$, basal membrane. 


\section{Discussion}

In this study, we found that vitrification of ovarian tissue or isolated preantral follicles did not lead to an increase in morphological or molecular markers of apoptosis compared to follicles in fresh ovarian tissue. Apoptosis normally occurs in granulosa cells of secondary and antral follicles at all stages of folliculogenesis [24], through either the extrinsic or intrinsic pathway. In our study, both FasL and caspase-3 expression were seen in granulosa cells, oocytes, and stroma of preantral follicles from both fresh and vitrified-thawed ovarian cortex samples.

Our results are consistent with those of Sheikhi et al. [8,28], who also reported normal human follicle morphology after vitrification based on an analysis of electron microscopy findings and caspase-3 expression. A non-randomized study by Keros et al. [29], in which 20 ovarian biopsy tissues were cryopreserved using slow freezing versus vitrification, found no significant difference in the number and morphology of follicles between the two groups.

Cryopreservation of preantral follicles can be performed while the follicles remain within the ovarian cortex or following enzymatic and mechanical isolation of the follicles. Most studies have reported the cryopreservation of follicles within the ovarian cortex, rather than of isolated preantral follicles [30]. We showed no significant difference in apoptosis markers between preantral follicles vitrified and thawed within the ovarian cortex or as isolated follicles. In addition, we showed no significant difference in apoptosis markers among preantral follicles isolated using three different enzymatic protocols, with Liberase $\mathrm{DH}$, collagenase, and DNAse. In addition, the expression of the apoptosis markers FasL and caspase-3 were not significantly different between freshly isolated and vitrified-thawed preantral follicles.

Our yield of 161 preantral follicles isolated from the ovarian cortex tissues from six women is similar to that reported by Hovatta et al. [31], who isolated 248 primordial follicles from women 25-41 years of age. The most follicles were successfully isolated from women less than 35 years of age with serum AMH levels above $1.4 \mathrm{ng} / \mathrm{mL}$ (Table 2). This result is consistent with that of Wiweko et al. [32], who reported that a serum AMH level of $1.4 \mathrm{ng} / \mathrm{mL}$ was the best predictor to determine the follicle reserve (number of primordial follicles) and ovarian age. Age is one of the most important factors in the success of fertility preservation. This study revealed no significant difference in morphology of isolated preantral follicles from fresh and vitrifiedthawed ovarian cortex samples. Wiweko et al. $[32,33]$ reported the same results among four women 31-37 years old.

Preantral follicle isolation in this study was carried out using a combination of enzymatic methods and mechanical dissection given the very dense stroma and cortex of human ovarian tissue. The use of DNAse helps to destroy the connective tissue DNA of the ovarian stroma because the isolation process can cause cell clumps, which cause the follicle to be incompletely isolated [31,34]. Previously, we reported that the addition of DNAse in follicular isolation resulted in a clearer picture of the preantral follicle [33]. In accordance with the previous study, the findings of this study showed a better result compared with several previous studies that utilized only Liberase to isolate preantral follicles $[25,35]$.

The addition of DNAse allowed the incubation time to be reduced to 60 minutes in the Liberase group and 45 minutes in the collagenase group. It has been proven that partial isolation of human ovarian follicles can be performed using a combination method of 0.25 $\mathrm{mg} / \mathrm{mL}$ and $0.5 \mathrm{mg} / \mathrm{mL}$ collagenase for $1-2$ hours followed by mechanical dissection using a 27-G needle [29]. Furthermore, more follicles were successfully isolated using enzymatic methods than when using mechanical dissection. However, enzymatic methods undermine the integrity of the follicle, resulting in lower oocyte survival [31]. To prevent this, we reduced the incubation time to 75 minutes (Liberase), 60 minutes (Liberase+DNAse) and 45 minutes (collagenase+DNAse).

To our knowledge, this is the first study to report no significant difference in the number, morphology, and survival rate of preantral follicles isolated from fresh and vitrified-thawed human ovarian samples. A novel aspect of this study is the use of the preantral follicle vitrification method of Kagawa et al. [19] with the cryovial device, which is also used for ovarian tissue vitrification. The follicle isolation procedures used in this study resulted in viable follicles with intact basal membranes and zona pellucida, which is important for the follicle to survive after vitrification. A good zona pellucida and basal membrane are also very important for the in vitro culture of follicles.

An apoptosis analysis and in vitro culture were done to evaluate the survival of follicles after vitrification. The expression levels of Fas $L$ and caspase-3 mRNA were evaluated because vitrification is known to stimulate the extrinsic and common pathway of intrafollicular apoptosis [24]. Caspase-3 was expressed in theca cells of the corpus luteum and granulosa cell of atretic follicles. Increases in both FasL and caspase-3 would be expected to initiate apoptosis in granulosa cells. This study revealed no significant difference in the expression of either FasL or caspase-3 mRNA, suggesting that vitrification of preantral follicles did not stimulate apoptosis in granulosa cells.

In vitro culture of isolated fresh preantral follicles was the most technically challenging part of this study. Both Dolmans et al. [25] and Vanacker et al. [35] did not report culturing isolated follicles. Preantral follicle culture provides a way to evaluate follicle survival and health after vitrification. Only one secondary follicle isolated from a fresh ovarian cortex sample developed into an antral follicle in culture; the follicle was isolated from a woman younger than 35 years of age with a serum AMH level above $1.4 \mathrm{ng} / \mathrm{mL}$ (Table 6). Serum AMH is related to the number of follicles, but is not directly related to follicle quality. It has been found that biological age is not identical to 
chronological age, because it is also determined by genetics and environmental factors [32].

The main issue now is how to develop an appropriate in vitro gametogenesis system that can preserve the three-dimensional structure of isolated ovarian follicles and enable their full growth and development. Isolated preantral follicles need extracellular matrix for nutrition and oxygen supplementation during growth and development in vitro, and it has been previously reported that synthetic extracellular matrix from alginate beads could support the growth of macaque preantral follicles in vitro [36]. A limitation of the present study is the relatively small number of subjects; therefore, further studies with more subjects comparing the capacity of fresh and vitrified-thawed preantral follicles to grow in a three-dimensional culture system are needed.

It was shown that vitrification did not affect preantral follicle morphology and mRNA expression of the apoptotic markers FasL and caspase-3, in either preantral follicles within ovarian cortex samples or isolated preantral follicles. Further studies are required to establish whether vitrification affects the in vitro culture of preantral follicles, and future research could investigate the in vitro culture of human preantral follicles using an alginate bead synthetic extracellular matrix.

\section{Conflict of interest}

No potential conflict of interest relevant to this article was reported.

\section{Acknowledgments}

The authors would like to thank Kresna Mutia, Pritta Amelia, Dwinarsi Yusuf, Eliza Mansyur, Tita Yuningsih, and all of the clinicians and staff of the Division of Reproductive Endocrinology and Infertility, Department of Obstetrics and Gynecology, Faculty of Medicine Universitas Indonesia.

\section{ORCID}

Budi Wiweko https://orcid.org/0000-0002-5898-7034

\section{References}

1. Maltaris T, Boehm D, Dittrich R, Seufert R, Koelbl H. Reproduction beyond cancer: a message of hope for young women. Gynecol Oncol 2006;103:1109-21.

2. Meirow D. Reproduction post-chemotherapy in young cancer patients. Mol Cell Endocrinol 2000;169:123-31.

3. Nottola SA, Camboni A, Van Langendonckt A, Demylle D, Macchiarelli G, Dolmans MM, et al. Cryopreservation and xenotrans- plantation of human ovarian tissue: an ultrastructural study. Fertil Steril 2008;90:23-32.

4. Donnez J, Martinez-Madrid B, Jadoul P, Van Langendonckt A, Demylle $D$, Dolmans MM. Ovarian tissue cryopreservation and transplantation: a review. Hum Reprod Update 2006;12:519-35.

5. Martinez-Madrid B, Camboni A, Dolmans MM, Nottola S, Van Langendonckt A, Donnez J. Apoptosis and ultrastructural assessment after cryopreservation of whole human ovaries with their vascular pedicle. Fertil Steril 2007;87:1153-65.

6. Revel A, Revel-Vilk S, Aizenman E, Porat-Katz A, Safran A, BenMeir $A$, et al. At what age can human oocytes be obtained? Fertil Steril 2009;92:458-63.

7. Diedrich K, Fauser BC, Devroey P; Evian Annual Reproduction (EVAR) Workshop Group 2009. Cancer and fertility: strategies to preserve fertility. Reprod Biomed Online 2011;22:232-48.

8. Sheikhi M, Hultenby K, Niklasson B, Lundqvist M, Hovatta O. Clinical grade vitrification of human ovarian tissue: an ultrastructural analysis of follicles and stroma in vitrified tissue. Hum Reprod 2011;26:594-603.

9. von Wolff M, Donnez J, Hovatta O, Keros V, Maltaris T, Montag M, et al. Cryopreservation and autotransplantation of human ovarian tissue prior to cytotoxic therapy: a technique in its infancy but already successful in fertility preservation. Eur J Cancer 2009; 45:1547-53.

10. Rosendahl M, Schmidt KT, Ernst E, Rasmussen PE, Loft A, Byskov AG, et al. Cryopreservation of ovarian tissue for a decade in Denmark: a view of the technique. Reprod Biomed Online 2011;22: 162-71.

11. Gosden RG, Baird DT, Wade JC, Webb R. Restoration of fertility to oophorectomized sheep by ovarian autografts stored at -196 degrees C. Hum Reprod 1994;9:597-603.

12. Santos RR, Amorim C, Cecconi S, Fassbender M, Imhof M, Lornage J, et al. Cryopreservation of ovarian tissue: an emerging technology for female germline preservation of endangered species and breeds. Anim Reprod Sci 2010;122:151-63.

13. Hussein MR, Bedaiwy MA, Falcone T. Analysis of apoptotic cell death, BCl-2, and p53 protein expression in freshly fixed and cryopreserved ovarian tissue after exposure to warm ischemia. Fertil Steril 2006;85 Suppl 1:1082-92.

14. Buyuk E, Oktem O, Sonmezer M, Oktay KH. Ovarian tissue cryopreservation and other fertility preservation strategies. In: Gardner DK, Weissman A, Howles CM, Shoham Z, editors. Textbook of assisted reproductive technologies: laboratory and clinical perspectives. 3rd ed. London: Informa; 2009. p. 327-41.

15. Gosden RG, Mullan J, Picton HM, Yin H, Tan SL. Current perspective on primordial follicle cryopreservation and culture for reproductive medicine. Hum Reprod Update 2002;8:105-10. 
16. Hovatta O, Silye R, Krausz T, Abir R, Margara R, Trew G, et al. Cryopreservation of human ovarian tissue using dimethylsulphoxide and propanediol-sucrose as cryoprotectants. Hum Reprod 1996; 11:1268-72.

17. Hovatta O. Methods for cryopreservation of human ovarian tissue. Reprod Biomed Online 2005;10:729-34.

18. Vajta G, Nagy ZP. Are programmable freezers still needed in the embryo laboratory? Review on vitrification. Reprod Biomed Online 2006;12:779-96.

19. Kagawa N, Silber S, Kuwayama M. Successful vitrification of bovine and human ovarian tissue. Reprod Biomed Online 2009;18: 568-77.

20. Bian J, Li T, Ding C, Xin W, Zhu B, Zhou C. Vitreous cryopreservation of human preantral follicles encapsulated in alginate beads with mini mesh cups. J Reprod Dev 2013;59:288-95.

21. Khosravi F, Reid RL, Moini A, Abolhassani F, Valojerdi MR, Kan FW. In vitro development of human primordial follicles to preantral stage after vitrification. J Assist Reprod Genet 2013;30:1397-406.

22. Markstrom E, Svensson EC, Shao R, Svanberg B, Billig H. Survival factors regulating ovarian apoptosis: dependence on follicle differentiation. Reproduction 2002;123:23-30.

23. Johnson AL, Bridgham JT. Caspase-mediated apoptosis in the vertebrate ovary. Reproduction 2002;124:19-27.

24. Hussein MR. Apoptosis in the ovary: molecular mechanisms. Hum Reprod Update 2005;11:162-77.

25. Dolmans MM, Michaux N, Camboni A, Martinez-Madrid B, Van Langendonckt $A$, Nottola $S A$, et al. Evaluation of Liberase, a purified enzyme blend, for the isolation of human primordial and primary ovarian follicles. Hum Reprod 2006;21:413-20.

26. Peduto Eberl L, Guillou L, Saraga E, Schroter M, French LE, Tschopp J, et al. Fas and Fas ligand expression in tumor cells and in vascular smooth-muscle cells of colonic and renal carcinomas. Int J Cancer 1999;81:772-8.

27. Sobenin IA, Bobryshev YV, Korobov GA, Borodachev EN, Postnov
AY, Orekhov AN. Quantitative analysis of the expression of caspase 3 and caspase 9 in different types of atherosclerotic lesions in the human aorta. Exp Mol Pathol 2015;99:1-6.

28. Sheikhi M, Hultenby K, Niklasson B, Lundqvist M, Hovatta O. Preservation of human ovarian follicles within tissue frozen by vitrification in a xeno-free closed system using only ethylene glycol as a permeating cryoprotectant. Fertil Steril 2013;100:1707.

29. Keros V, Xella S, Hultenby K, Pettersson K, Sheikhi M, Volpe A, et al. Vitrification versus controlled-rate freezing in cryopreservation of human ovarian tissue. Hum Reprod 2009;24:1670-83.

30. Amorim CA, Goncalves PB, Figueiredo JR. Cryopreservation of oocytes from pre-antral follicles. Hum Reprod Update 2003;9: 119-29.

31. Hovatta O, Wright C, Krausz T, Hardy K, Winston RM. Human primordial, primary and secondary ovarian follicles in long-term culture: effect of partial isolation. Hum Reprod 1999;14:2519-24.

32. Wiweko B, Prawesti DM, Hestiantoro A, Sumapraja K, Natadisastra M, Baziad A. Chronological age vs biological age: an age-related normogram for antral follicle count, FSH and anti-Mullerian hormone. J Assist Reprod Genet 2013;30:1563-7.

33. Wiweko B, Mutia K, Mansyur E. Follicle isolation from ovarian tissue before and after cryopreservation. Fertil Steril 2013;100: S185-6.

34. Schroder CP, Timmer-Bosscha H, Wijchman JG, de Leij LF, Hollema $\mathrm{H}$, Heineman $\mathrm{MJ}$, et al. An in vitro model for purging of tumour cells from ovarian tissue. Hum Reprod 2004;19:1069-75.

35. Vanacker J, Camboni A, Dath C, Van Langendonckt A, Dolmans MM, Donnez J, et al. Enzymatic isolation of human primordial and primary ovarian follicles with Liberase $\mathrm{DH}$ : protocol for application in a clinical setting. Fertil Steril 2011;96:379-83.

36. Telfer EE, Zelinski MB. Ovarian follicle culture: advances and challenges for human and nonhuman primates. Fertil Steril 2013;99: 1523-33. 